\title{
Does drinking location matter? Profiles of risky single-occasion drinking by location and alcohol-related harm among young men
}

\section{Caroline Bähler ${ }^{1}$, Michelle Dey ${ }^{1,2}$, Petra Dermota ${ }^{1}$, Simon Foster ${ }^{1}$, Gerhard Gmel ${ }^{3}$ and Meichun Mohler-Kuo ${ }^{1}$ *}

1 Institute of Social and Preventive Medicine, University of Zurich, Zurich, Switzerland

${ }^{2}$ Melbourne School of Population and Global Health, University of Melbourne, Melbourne, VIC, Australia

${ }^{3}$ Alcohol Treatment Centre, Lausanne University Hospital (CHUV), Lausanne, Switzerland

\section{Edited by:}

Shervin Assari, University of

Michigan, USA

\section{Reviewed by:}

Arezoo Shajiei, Mashhad University of Medical Sciences, Iran

Navvab Shamspour, Iranain Red

Crescent Society, Iran

Mahshid Taj, World Health

Organization, Egypt

Anahita Bassirnia, Mount Sinai Beth

Israel, USA

*Correspondence:

Meichun Mohler-Kuo, Institute of

Social and Preventive Medicine,

University of Zurich, Hirschengraben

84, Zurich 8001, Switzerland

e-mail:meichun.mohler-kuo@uzh.ch
In adolescents and young adults, acute consequences like injuries account for a substantial proportion of alcohol-related harm, especially in risky single-occasion (RSO) drinkers. The primary aim of the study was to characterize different drinking profiles in RSO drinkers according to drinking locations and their relationship to negative, alcohol-related consequences. The sample consisted of 2746 young men from the Cohort Study on Substance Use Risk Factors who had reported drinking six or more drinks on a single-occasion at least monthly over the preceding 12 months. Principal component analysis on the frequency and amount of drinking at 11 different locations was conducted, and 2 distinguishable components emerged: a non-party-dimension (loading high on theater/cinema, sport clubs, other clubs/societies, restaurants, and sport events) and a party-dimension (loading high on someone else's home, pubs/bars, discos/nightclubs, outdoor public places, special events, and home). Differential impacts of drinking location profiles were observed on severe negative alcohol-related consequences (SAC). Relative to those classified as low or intermediate in both dimensions, no significant difference experiencing SAC was found among those who were classified as high in the non-party-dimension only. However, those who were classified as high in the party-dimension alone or in both dimensions were more likely to experience SAC. These differential effects remained after adjusting for alcohol consumption (volume and risky single-occasion drinking), personality traits, and peer-influence [adjusted $\mathrm{OR}=0.83$ (0.68-1.02), 1.57 (1.27-1.96), and 1.72 (1.23-2.41), respectively], indicating independent effects of drinking location on SAC. The inclusion of sociodemographic factors did not alter this association. The fact that this cluster of party-dimension locations seems to predispose young men to experiencing SAC has important implications for alcohol control policies.

Keywords: drinking locations, drinking profiles, risky single-occasion drinking, negative alcohol-related consequences

\section{INTRODUCTION}

From the public health perspective, risky single-occasion drinking (RSOD) is considered one of the major problems stemming from alcohol consumption among adolescents and young adults. RSOD has been consistently identified as a stronger predictor of negative alcohol-related consequences among young adults than total drinking volume (1-4). According to the literature, acute consequences like injuries account for a substantial proportion of alcohol-related harm, especially in young people (5-7). In fact, acute consequences of RSOD rank among the main risk factors for mortality and morbidity in late adolescence and early adulthood $(7,8)$. While the negative consequences of problematic alcohol consumption in young men are well-known, less is known about the relationship between different drinking situations and the consequences of RSOD. Individual factors cannot be the only explanatory variables, as the drinking behavior of the same individual may vary in different settings (9). According to Knibbe et al. (10), exposure to an alcohol-stimulating environment is even more decisive than alcohol-specific beliefs or norms. This might be especially true in a country like Switzerland, where alcohol consumption is integrated into everyday life and where drinking places are multifaceted and likely to influence drinking behavior and its consequences in different ways (1). Previous results have shown that approximately $80 \%$ of alcohol consumption does not take place at home or at someone else's home, but in public places like bars, discos, and festivals (11).

To investigate the relationship between drinking and alcoholrelated consequences, not only drinking pattern - including the frequency and volume of drinking over a given time period but also the demographics (i.e., male gender, age), psychological state (i.e., personality, attitudes), and social context (i.e., peerinfluence, drinking locations) of drinkers must be considered (9, 
12). A more differentiated understanding of individual and environmental circumstances that contribute to the risk of negative alcohol-related consequences has emerged, revealing risk factors related to the time-frame of drinking and belonging to specific subgroups (13). Given this, considering the differential impact of social embedding of drinking locations on negative alcohol-related consequences could contribute significantly to our understanding of problematic alcohol consumption. However, studies to date have predominantly been conducted in the USA and Canada, and many papers dealing with situational drinking settings have looked specifically at university/campus life (13-16).

The primary aim of the present study was to characterize drinking profiles according to drinking location and their differential impact on negative alcohol-related consequences in a populationbased Swiss sample. It can be assumed that specific drinking locations and occasions are associated with a lack of supervision and social control, thereby raising the likelihood of negative consequences. Findings should have further implications for public health interventions aimed at lowering problematic alcohol consumption in young people, which is one of the main strategic goals of the National Alcohol Program 2013-2016 of the Swiss Federal Office of Public Health (17).

\section{MATERIALS AND METHODS}

All analyses conducted for this study were based on data collected for the Cohort Study on Substance Use Risk Factors (C-SURF). The study design and study sample for C-SURF have been detailed elsewhere (18). The study protocol was approved by the Ethics Committee for Clinical Research at Lausanne University Medical School (Protocol No. 15/07). In brief, participants were enrolled between 23 August 2010 and 15 November 2011 at three out of six Swiss army recruitment centers - in Lausanne (French-speaking), Windisch and Mels (German-speaking) - encompassing 21 of 26 Swiss cantons. As army recruitment is mandatory in Switzerland, all young men of roughly 19 years of age were eligible for study inclusion (i.e., no pre-selection to army conscription exists).

\section{PARTICIPANTS}

Out of the 15,074 young men who showed up at the recruitment centers, $1829(12.1 \%)$ were not seen by the research staff. Among the 13,245 conscripts who were informed about the study, $7563(57.1 \%)$ gave written informed consent to participate, among whom 5990 (79.2\%) subsequently filled out the baseline questionnaire. For the purposes of this study, only those men who reported having consumed six or more standard drinks on a single-occasion at least monthly over the preceding 12 months were included in analysis [2746 (45.8\%) of the 5990 C-SURF participants], as risky single-occasion (RSO) drinking contributes substantially to the risk of alcohol-related harm in young men. Fifty participants had to be excluded due to missing data on drinking locations. Hence, ultimately, the sample consisted of 2696 subjects.

\section{MEASURES}

\section{Drinking measures}

Drinking volume (the average number of drinks per week) was calculated by multiplying the usual frequency (rescaled to days per week) and the usual quantity (number of standard drinks per occasion) of the past 12 months. RSOD was defined in accordance with Murgraff et al. (19), as consuming at least six standard drinks on a single-occasion. This, in turn, was divided into three categories: monthly, weekly, and daily. RSOD referred to the last 12 months, as well. Standard drinks containing 10-12 g of pure alcohol were depicted in the questionnaire.

\section{Drinking locations}

Drinking locations were categorized according to the $2000 \mathrm{New}$ Zealand National Alcohol Tracking Survey (20). For each location, the usual frequency and usual amount of drinking over the previous 12 months was assessed. Frequency was divided into eight categories, ranging from "never" to "daily" and was rescaled to the number of days per week. The amount per occasion was divided into six categories ranging from " 1 to 2 standard drinks per occasion" to " 12 or more standard drinks per occasion" and was rescaled to the average number of standard drinks per occasion.

\section{Severe negative alcohol-related consequences}

Participants were asked whether or not they had experienced negative consequences associated with drinking alcohol over the previous 12 months. To date, no standardized grouping of consequences from drinking exists for epidemiological surveys (21). For our study, the following negative alcohol-related consequences were included, all considered more serious alcohol-related consequences by Wechsler et al. (22): unintended or unprotected sexual intercourse; an accident or injury; conflicts with police/authorities; arguments or fights; property damage. Responses to questions regarding these severe negative alcohol-related consequences (SAC) were dichotomized into "yes" if one or more of the six consequences had occurred or "no." Extensive analyses of various subgroups of consequences (e.g., looking at sexual or aggressive behaviors separately) failed to reveal any substantial differences in the impact of profile groups by drinking location.

\section{Sociodemographic factors}

The following sociodemographic factors were assessed by means of self-report: subject age (younger than 20 vs. 20 years or older); type of residence, defined as "rural" ( $<10,000$ inhabitants) or "urban" ( $\geq 10,000$ inhabitants); and linguistic region, defined as "German" or "French." Furthermore, data concerning family affluence (categorized into "above average income," "average income," and "below average income"), the highest achieved education of the study subject (categorized into "primary school," "higher vocational school," and "high school/university"), and the highest achieved education of the father (categorized into "no secondary education," "secondary education," and "tertiary education") were included in analysis.

\section{Personality factors}

Sensation seeking. This personality trait was measured using the Brief Sensation Seeking Scale (BSSS) (23), a scale consisting of eight items, with participants asked to score each statement from 1 (strongly disagree) to 5 (strongly agree).

Anxiety/neuroticism, aggression/hostility and sociability. Three different personality traits were measured, in accordance with 
the Zuckerman-Kuhlmann Personality scale (ZKPQ-50-cc) (24). Each scale consists of 10 items, with subjects asked whether or not they agreed with each of the corresponding statements ( 0 disagree, 1 agree).

\section{Peers}

Finally, subjects were asked whether any of their closest friends had what they would call a "significant drinking problem" - meaning one that did or should have led to treatment. Answer categories were as follows: "no one," "one or two," "some of them," and "most of them."

\section{DATA ANALYSIS}

Continuous variable data are presented as medians and interquartile ranges (IQR), and categorical variable data as percentages. Principle component analysis (PCA) of drinking location was conducted to identify variable combinations. Each of the resulting components was then classified into three categories, according to their factor scores. For this purpose, two cut-off values at the 33.3 and the 66.6 percentiles were applied, and the components divided into low ( $\leq 33.3$ percentile), intermediate $(>33.3$ and $\leq 66.6$ percentile), and high ( $>66.6$ percentile), as per their factor scores. Logistic regression models were used to evaluate the associations between SAC and the drinking profiles identified by PCA. SAC served as the dependent variable, and the drinking profiles as independent. Adjustments were made for sociodemographic variables (age, type of residence, linguistic region, family affluence, highest achieved education of the participant, and highest achieved education of the father), personality factors (sensation seeking, anxiety/neuroticism, aggression/hostility, and sociability), and peer-influence in logistic regression models. Classification of cases served to evaluate model adequacy. Statistical analyses were performed using SPSS version 21.0.

\section{RESULTS \\ CHARACTERIZING DRINKING LOCATION PROFILES}

To investigate whether drinking locations might cluster in a way as to identify different dimensions of drinking profiles, PCA with varimax rotation was conducted on the frequency and amount of drinking at the 11 different types of location. The factor analysis was exploratory, and two distinguishable components emerged. The two resulting components explained $56.1 \%$ of the total variance in the grouping items. The first component was termed as a non-party-dimension and included a total of five drinking location items with loadings between 0.65 and 0.86 . The second component was termed a party-dimension, incorporating six locations with loadings between 0.51 and 0.74 (Table 1 ). The non-partydimension loaded highly for theater/cinema, sport clubs (e.g., football, hockey, gymnastics), other clubs/societies (orchestra, choir, chess club etc.), restaurants, and sports events. In contrast, the party-dimension loaded highly for someone else's home, pubs/bars, discos/nightclubs, outdoor public places (e.g., parks, swimming pools, streets), special events (e.g., festivals, street parties, carnival, markets, exhibitions, concerts), and at home. Drinking at home was the drinking location with the smallest difference in loading between the two dimensions, meaning that this location contributed the least to any distinction between them.
Table 1 | Principal component analysis on drinking locations with varimax-rotated factor solutions $(n=2696)$.

\begin{tabular}{lcc}
\hline Item & $\begin{array}{c}\text { Non-party- } \\
\text { dimension }\end{array}$ & $\begin{array}{c}\text { Party- } \\
\text { dimension }\end{array}$ \\
\hline Theater/cinema & 0.86 & 0.12 \\
Sport clubs (e.g., football, hockey, gymnastics) & 0.82 & 0.24 \\
Other clubs/societies (orchestra, choir, chess & 0.78 & 0.25 \\
club etc.) & & \\
Restaurants & 0.70 & 0.34 \\
Sports events & 0.65 & 0.38 \\
Pubs/bars & 0.13 & 0.74 \\
Someone else's home & 0.25 & 0.73 \\
Discos/nightclubs & 0.21 & 0.69 \\
Outdoor public places (e.g., parks, swimming & 0.25 & 0.62 \\
pools, streets) & & \\
Special events (e.g., festivals, street parties, & 0.16 & 0.58 \\
exhibitions) & & \\
Home & 0.30 & 0.51 \\
\hline
\end{tabular}

\section{DRINKING PROFILES}

The factor scores from the two resulting PCA components were each divided into three categories (low, intermediate, and high). Consequently, subjects were allocated to one of four profile categories: (1) subjects who had low to intermediate factor scores for both the non-party-dimension and party-dimension (LL, $n=1115)$; (2) those who only had high scores for the non-partydimension ( $\mathrm{NH}, n=683$ ); (3) those who only had high scores for the party-dimension ( $\mathrm{PH}, n=682)$; and (4) those who had high scores for both dimensions $(\mathrm{HH}, n=216)$. The mean ages for the four profiles were $19.83(\mathrm{SD}=1.10), 19.91(\mathrm{SD}=1.26)$, $19.98(\mathrm{SD}=1.10)$, and $19.88(\mathrm{SD}=1.09)$, respectively. Baseline characteristics for these four profiles are shown in Tables 2 and 3.

\section{SEVERE NEGATIVE ALCOHOL-RELATED CONSEOUENCES}

Almost half (48.9\%) of our subjects reported having experienced SAC within the previous 12 months $(42.7 \%$ among those within the LL profile group, $39.3 \%$ among $\mathrm{NH}, 63.1 \%$ among $\mathrm{PH}$, and $66.2 \%$ among those within the $\mathrm{HH}$ profile group). The most frequently mentioned consequences within the LL profile group were accident or injury (16.8\%), unintended sexual intercourse (15.5\%), and arguments or fights (14.6\%). Corresponding figures were 14.0, 17.8, and $16.3 \%$ within the $\mathrm{NH}$ profile group, 28.9, 27.5, and $28.2 \%$ within the $\mathrm{PH}$ profile group, and 31.5 , 33.3, and $32.4 \%$ within the $\mathrm{HH}$ profile group.

Analysis revealed differential impacts of drinking location profiles on SAC among young adults who engaged in RSO within the preceding 12 months. Relative to those classified as low or intermediate for both dimensions, no significant difference in SAC was detected among those classified as high for the nonparty-dimension alone [crude OR $(95 \% \mathrm{CI})=0.87(0.72-1.06)]$. However, those classified as high for the party-dimension alone or for both dimensions were more likely to report having experienced SAC: crude OR $=2.30(1.89-2.79)$ in the $\mathrm{PH}$ profile group and 2.63 (1.94-3.57) in the $\mathrm{HH}$ profile group. 
Table 2 | Baseline characteristics of the four drinking profiles ${ }^{a}$ by drinking location

\begin{tabular}{lcccc}
\hline $\begin{array}{l}\text { Baseline characteristics } \\
n(\%)\end{array}$ & $\mathrm{LL}$ & $\mathrm{NH}$ & $\mathrm{PH}$ & $\mathrm{HH}$ \\
$(n=1115)$ & $(n=683)$ & $(n=682)$ & $(n=216)$
\end{tabular}

\begin{tabular}{lcccc}
\hline RESIDENCE & $669(60.0)$ & $476(69.7)$ & $425(62.3)$ & $154(71.3)$ \\
Rural & $446(40.0)$ & $207(30.3)$ & $257(37.7)$ & $62(28.7)$ \\
Urban & & & & \\
LINGUISTIC REGION & $526(47.2)$ & $380(55.6)$ & $254(37.2)$ & $103(47.7)$ \\
German & $589(52.8)$ & $303(44.4)$ & $428(62.8)$ & $113(52.3)$ \\
French & & & & \\
FAMILY AFFLUENCE & $517(46.4)$ & $333(48.8)$ & $308(45.2)$ & $99(45.8)$ \\
Above average income & $455(40.8)$ & $259(37.9)$ & $297(43.5)$ & $89(41.2)$ \\
Average income & $143(12.8)$ & $91(13.3)$ & $77(11.3)$ & $28(13.0)$ \\
Below average income & & & & \\
EDUCATION PARTICIPANT & & & & \\
Primary school & $581(52.8)$ & $340(50.7)$ & $310(46.5)$ & $95(44.4)$ \\
Higher vocational school & $266(24.1)$ & $208(31.0)$ & $217(32.5)$ & $77(36.0)$ \\
High school/university & $254(23.1)$ & $123(18.3)$ & $140(21.0)$ & $42(19.6)$ \\
$\begin{array}{l}\text { EDUCATION FATHER }{ }^{\mathbf{b}} \\
\text { No secondary education }\end{array}$ & $89(8.1)$ & $49(7.3)$ & $44(6.5)$ & $15(7.0)$ \\
$\begin{array}{l}\text { Secondary education } \\
\text { Tertiary education }\end{array}$ & $570(51.6)$ & $374(55.4)$ & $370(54.7)$ & $123(57.2)$ \\
& $445(40.3)$ & $252(37.3)$ & $263(38.8)$ & $77(35.8)$
\end{tabular}

${ }^{a} \mathrm{~L} L$, participants with low to intermediate factor scores for both dimensions; $\mathrm{NH}$ participants with high factor scores for the non-party-dimension only; $\mathrm{PH}$, participants with high factor scores for the party-dimension only; $\mathrm{HH}$, participants with high factor scores for both dimensions.

${ }^{b} \mathrm{~N}$ varied slightly due to missing data.

Table 3 | Personality traits of the four drinking profiles ${ }^{\text {a }}$ by drinking location

\begin{tabular}{lllll}
\hline $\begin{array}{l}\text { Personality traits } \\
\text { (median; IOR) }\end{array}$ & \multicolumn{1}{c}{$\mathbf{L L}$} \\
$(\boldsymbol{n}=\mathbf{1 1 1 5})$ & $\begin{array}{c}\mathbf{N H} \\
(\boldsymbol{n}=\mathbf{6 8 3})\end{array}$ & $\begin{array}{c}\mathbf{P H} \\
(\boldsymbol{n}=\mathbf{6 8 2})\end{array}$ & $\begin{array}{c}\mathbf{H H} \\
(\boldsymbol{n}=\mathbf{2 1 6})\end{array}$ \\
\hline Sensation seeking & 3.3 & 3.1 & 3.6 & 3.6 \\
& $(2.9-3.8)$ & $(2.6-3.8)$ & $(3.0-4.0)$ & $(3.0-4.3)$ \\
Anxiety/neuroticism & $1(0-3)$ & $1(1-3)$ & $1(0-3)$ & $1(0-3)$ \\
Aggression/hostility & $4(3-6)$ & $4(3-6)$ & $5(3-7)$ & $5(3-7)$ \\
Sociability & $7(5-8)$ & $7(5-8)$ & $7(5-8)$ & $7(6-8)$ \\
\hline
\end{tabular}

${ }^{a} L L$, participants with low to intermediate factor scores for both dimensions; $N H$ participants with high factor scores for the non-party-dimension only; $\mathrm{PH}$, participants with high factor scores for the party-dimension only; $\mathrm{HH}$, participants with high factor scores for both dimensions.

In order to rule out the possibility that the higher odds of experiencing SAC was solely explained by more drinks being consumed at specific locations, we further adjusted for drinking volume in a regression model. The median (IQR) drinking volumes for the LL, $\mathrm{NH}, \mathrm{PH}$, and $\mathrm{HH}$ profile groups were 8 (5-12), 8 (5-12), 14 (9-20), and $16(10-30)$ standard drinks per week, respectively. Frequency of RSO drinking (monthly vs. weekly vs. daily) also was included in the regression model. After adjusting for drinking volume and RSOD, the OR for SAC was still not significant within the $\mathrm{NH}$ profile group [0.83 $(0.68-1.00), p=0.055]$. In the $\mathrm{PH}$ profile group,
Table 4 | Logistic regression models of drinking profiles and sociodemographic variables on negative alcohol-related consequences $(n=2620)$.

OR $(95 \% \mathrm{Cl}) \quad p$-Value

\section{SEVERE NEGATIVE ALCOHOL-RELATED CONSEQUENCES (SAC)}

Drinking profiles ${ }^{\mathrm{a}}$

$\mathrm{LL} \quad 1.00$

$$
\mathrm{NH}
$$

$0.83(0.68-1.01)$

0.062

$\mathrm{PH}$

$1.79(1.45-2.21) \quad<0.001$

$\mathrm{HH}$

$\mathrm{RSOD}^{\mathrm{b}}$

\section{Monthly}

$1.94(1.40-2.69) \quad<0.001$

Weekly

Daily

$\begin{array}{cr}1.00 & \\ 1.61(1.35-1.93) & <0.001 \\ 2.74(1.54-4.87) & 0.001 \\ 1.01(1.00-1.02) & 0.043 \\ 1.03(0.87-1.23) & 0.702\end{array}$

Age

$1.03(0.87-1.23)$

0.702

Residence

Rural

1.00

Urban

$1.16(0.98-1.38)$

0.087

Linguistic region

German

1.00

French

$1.06(0.88-1.26)$

0.543

Family affluence

Above average income

1.00

Average income

$1.03(0.80-1.34)$

0.810

Below average income

$0.93(0.72-1.20)$

0.564

Education participant

Primary school

Higher vocational school

1.00

High school/university

$1.11(0.89-1.39)$

0.346

$1.20(0.94-1.51)$

0.140

Education father

No secondary education

1.00

Secondary education

$1.13(0.81-1.57)$

0.472

Tertiary education

$0.97(0.81-1.16)$

0.712

${ }^{a} \mathrm{LL}$, participants with low to intermediate factor scores for both dimensions; $\mathrm{NH}$, participants with high factor scores for the non-party-dimension only; $\mathrm{PH}$, participants with high factor scores for the party-dimension only; HH, participants with high factor scores for both dimensions.

${ }^{b} R S O D$, risky single-occasion drinking.

the adjusted OR fell to $1.79(1.45-2.20, p<0.001)$, while the OR in the $\mathrm{HH}$ profile group was now $1.88(1.37-2.60, p<0.001)$. These results indicate that the effect of drinking location on SAC was only partially mediated through alcohol consumption.

In a second model, the association between the drinking location profiles and SAC was further adjusted for the sociodemographic factors - age, linguistic region, residence, highest achieved education of the participant, family affluence, and highest achieved education of the father (Table 4). However, all the above sociodemographic factors had no influence on the association between drinking profile and SAC. The differences in profile groups relative to SAC remained: $\mathrm{OR}=0.83(0.68-1.01, p=0.062)$ within the $\mathrm{NH}$ profile group relative to $\mathrm{LL} ; \mathrm{OR}=1.79(1.45-2.21, p<0.001)$ within the $\mathrm{PH}$ profile group; and $\mathrm{OR}=1.94(1.40-2.69, p<0.001)$ within the $\mathrm{HH}$ profile group. 
In contrast, when personality factors (sensation seeking, anxiety/neuroticism, aggression/hostility, and sociability) were included in regression analysis, the odds of SAC declined among those within the $\mathrm{PH}$ or $\mathrm{HH}$ profile group $[\mathrm{OR}=1.63$ (1.32-2.02), $p<0.001$, and $\mathrm{OR}=1.76(1.26-2.46), p=0.001$, respectively], and remained unchanged within the $\mathrm{NH}$ profile group $[\mathrm{OR}=0.83$ $(0.68-1.01), p=0.062]$. All the above personality traits - except for sociability - were significantly associated with an increased likelihood of SAC. However, personality traits failed to fully explain differences in the association between drinking profiles and acute negative alcohol-related consequences.

In a fourth and final model, the influence of peers with significant drinking problems was added to personality variables. This adjustment exerted a small influence on the association between drinking profiles and SAC. Again, the OR of the $\mathrm{NH}$ profile group did not change [OR $=0.83(0.68-1.02), p=0.075$ ], whereas the OR of SAC slightly decreased in the $\mathrm{PH}$ and $\mathrm{HH}$ profile groups $[\mathrm{OR}=1.57(1.27-1.96), p<0.001$, and $\mathrm{OR}=1.72(1.23-$ $2.41), p=0.001$, respectively] (Table 5). Approximately two-thirds $(64.0 \%)$ of subjects were correctly classified as having experienced negative alcohol-related consequences in this final model.

\section{DISCUSSION}

Principle component analysis on the frequency and amount of drinking at 11 different types of drinking location revealed two dimensions: a non-party-dimension that loaded highly for theater/cinema, sport clubs, other clubs/societies, restaurants, and sport events; and a party-dimension that loaded highly for drinking at someone else's home, pubs/bars, discos/nightclubs, outdoor public places, special events, and drinking at home.

Subsequent regression analysis revealed differential impacts of drinking location profiles on SAC among adolescents and young adults who had engaged in RSO drinking over the previous 12 months. Relative to those classified as low or intermediate for both dimensions, no significant difference in reported SAC was found among those classified as high for the non-partydimension only. However, those who were classified as high for the party-dimension alone or for both dimensions were more likely to experience SAC. These effects persisted after adjusting for a variety of variables, including the degree of alcohol consumption, indicating that drinking location has independent effects on drinking consequences.

Differences in the associations between the drinking profiles and alcohol-related problems were attenuated, but persisted after controlling for alcohol consumption (volume and RSOD), personality traits, and peer-influence, indicating independent effects of these variables on SAC. In contrast, including sociodemographic factors did not alter the associations. The self-selection hypothesis of choosing drinking locations based on personality traits (9) only explained some of the variability in drinking patterns and alcoholrelated consequences. Therefore, the cluster of locations that had high factor scores for the party-dimension seemed to predispose young men to experiencing SAC.

Location-specific differences related to RSOD and drinking problems have been examined in several previously published studies. In a study by Single and Wortley (25), drinking in bars and at parties was more strongly associated with self-reported drinking
Table 5 | Logistic regression models of drinking profiles, personality traits and peers on negative alcohol-related consequences $(n=2668$ ).

OR $(95 \% \mathrm{Cl}) \quad p$-Value

\section{SEVERE NEGATIVE ALCOHOL-RELATED CONSEQUENCES (SAC)}

Drinking profiles ${ }^{a}$

\begin{tabular}{llr} 
LL & 1.00 & \\
NH & $0.83(0.68-1.02)$ & 0.075 \\
PH & $1.57(1.27-1.96)$ & $<0.001$ \\
HH & $1.72(1.23-2.41)$ & 0.001 \\
RSOD & & \\
Monthly & 1.00 & \\
Weekly & $1.42(1.18-1.70)$ & $<0.001$ \\
Daily & $2.36(1.31-4.26)$ & 0.004 \\
Drinking volume (standard drinks per week) & $1.01(1.00-1.01)$ & 0.212 \\
Personality traits & & \\
Sensation seeking & $1.51(1.36-1.69)$ & $<0.001$ \\
Anxiety/neuroticism & $1.08(1.04-1.13)$ & $<0.001$ \\
Aggression/hostility & $1.16(1.12-1.21)$ & $<0.001$ \\
Sociability & $1.03(0.99-1.08)$ & 0.140 \\
Peers with significant drinking problems & & \\
None & 1.00 & \\
One or two & $1.59(0.91-2.78)$ & 0.104 \\
Some of them & $2.16(1.52-3.05)$ & $<0.001$ \\
Most of them & $1.37(1.12-1.66)$ & 0.002 \\
\hline
\end{tabular}

${ }^{a} \mathrm{LL}$, participants with low to intermediate factor scores for both dimensions; $\mathrm{NH}$, participants with high factor scores for the non-party-dimension only; $\mathrm{PH}$, participants with high factor scores for the party-dimension only; $\mathrm{HH}$, participants with high factor scores for both dimensions.

${ }^{b} R S O D$, risky single-occasion drinking.

problems over the past 12 months than drinking in restaurants, especially among young men. In that study, the strength of the association between drinking in bars and experiencing problems was attenuated, but still remained significant, after controlling for the level of consumption. As in our study, education was no longer significantly associated with drinking problems, once the relationship was controlled for drinking volume and RSOD (25).

Our results are also partly consistent with those of Stockwell et al. (26), who demonstrated that drinking in nightclubs is associated more strongly with alcohol-related harm than drinking in restaurants. A higher likelihood of negative drinking consequences during event-specific occasions like festivals was also reported in the latest review by Mallett et al. (13). However, to the best of our knowledge, none of the previous studies clustered drinking locations or assessed the association of these clusters on negative alcohol-related consequences.

Sociodemographic variables could not explain the difference in the association between drinking profile by drinking location and SAC. One reason could be that only young males were included in our study. Furthermore, our results are consistent with previous studies that failed to identify socio-economic status or age as independent predictors of alcohol-related consequences once drinking patterns were controlled for $(27,28)$. In addition, research has shown that peers may influence the association between drinking 
patterns and negative alcohol-related consequences (29). In the present analysis, the association was modified by the inclusion of the number of peers with significant drinking problems, though differences in the relationship persisted. However, the peer measure included in this model did not specifically look at RSOD, but rather at problematic alcohol consumption as a whole. A more differentiated peer variable might have had an even greater impact upon our results. As drinking is more often related to social interactions as many other health-relevant behaviors, preventive measures should take drinking situations, as expressions of different social interactions, into account (3).

\section{LIMITATIONS}

Our study has several potential limitations. First, all data were selfreported. Results may therefore be distorted because of assessment bias, recall bias, or social desirability. For example, students willing to experience consequences might have been more likely to report such consequences (13). Moreover, cultural differences attributing consequences to alcohol have been observed by others (21). Furthermore, expectations regarding the effect of alcohol consumption could have influenced the relationship between drinking profile and alcohol-related harm (30), it is conceivable that further factors might have influenced our study findings, such as family history or drinking companions. However, in the study by Wells et al. (31), drinking companions did not confound the relationship between alcohol consumption and alcohol-related aggression. Likewise, "pre-drinking" or "pre-gaming" could have confounded the association between drinking profile by drinking location and SAC $(13,14)$, even though we indirectly controlled for this behavior by including drinking volume. The comprehensive C-SURF questionnaire allowed us to control for a variety of sociodemographic and other individual variables. In addition, we did not control for drug use in our final model because the results did hardly change after including drug use. Moreover, drug use is illegal in Switzerland. Therefore, it is unlikely that the young men would use drugs in public places like restaurants. Thirdly, the study is subject to selection bias, in that all analyses were limited to young men. The results can therefore not be generalized to women or to older populations. Moreover, the relatively low response rate we observed creates the risk of selection bias. However, because we also obtained short screening questionnaires from $94 \%$ of all conscripts at the recruitment centers, we were able to analyze potential non-participation biases by different types of substance use, due to the need for informed consent. In addition, the differences between responders and non-responders among consenters were analyzed. Although some statistically significant differences were noted, they were small in magnitude, and their statistical significance largely due to the large sample. Even though consenters included more drinkers than non-consenters did, substance users were less likely to respond than non-users among consenters. These results have been published in detail elsewhere (18). Finally, the cross-sectional design does not allow for any causal conclusions to be drawn.

\section{IMPLICATIONS}

Numerous studies have demonstrated that problematic alcohol consumption, like RSO drinking, is widespread in young people
$(32,33)$; and that such consumption is associated with negative consequences $(2,3,5)$. The results of our study suggest that drinking location might have an important influence on alcohol-related harm above and beyond alcohol consumption per se. We discovered a cluster of drinking locations that are not bound to a specific type of drinker, like sensation seekers, indicating independent effects of drinking location on SAC. This, in turn, has important implications for alcohol control policies. It supports the need for structured measures like policies, regulations, and compliance checks tailoring this cluster of drinking locations to substantially reduce alcohol-related harm.

On one hand, compliance with alcohol policies and existing legislation at sensible locations with on-premise alcohol purchases like pubs/bars, discos/nightclubs, and special events - should be monitored more closely. For instance, continuing to serve obviously intoxicated customers has been shown to be the best predictor of negative alcohol-related consequences (26). However, studies conducted in Switzerland and the US have also revealed that compliance with legislation is far from satisfactory $(34,35)$. A further step could be the adoption of a designated drivers program to reduce drinking and driving (36). The recent introduction of graduated driver licensing in Switzerland will hopefully further reduce automobile collisions among young drivers (37). Additional statutory regulations are needed, such as claims for additional municipal charges for alcoholic beverages at special events (38). On the other hand, preventive measures are needed for off-premise alcohol sellers to reduce alcohol-related harm at locations like outdoor public places and at someone else's home. Such preventive measures should include restrictions related to outlet liability, alcohol price discounts, and selling hours (39). Moreover, as $89.9 \%$ of the participants still lived in their parents' home, parents also need to be sensitized to the cluster of places associated with alcohol-related harm. Increased parental monitoring and/or regulation might help to reduce negative consequences. In addition, although some of the Swiss campaigns and prevention programs have been designed to be location-specific - like "Safer Dance Swiss" referring to festivals, and "Safer Clubbing" referring to discos/nightclubs - the current results imply that interventions that target single drinking locations only will fall short of preventing SAC in RSO drinkers. The different interventions need to work hand in hand to reduce the burden of SAC. Furthermore, innovations are needed to protect people from the consequences of their binge-drinking behaviors, like free ride programs to ensure that drinkers travel home safely, analogous to proposed student volunteer escort services that assist students walking to their dorms (15).

The fact that negative alcohol-related consequences from RSOD may yet appear in the early adulthood emphasizes the need for timely preventive measures. Successful interventions in early life may not only reduce negative alcohol-related consequences during adolescence, but also prevent adult drinking problems (29).

In summary, it can be stated that a structure of timely preventive measures is needed to reduce alcohol-related harm. However, as the availability of alcoholic beverages is high and there is a long tradition of including alcohol consumption in daily life in Switzerland, the implementation of structural changes poses several challenges (38), something that was illustrated impressively during the latest parliamentary debate in the fall of 2013. 


\section{CONCLUSION}

The present findings suggest that problematic alcohol consumption and negative alcohol-related consequences are strongly associated with a cluster of specific drinking locations. This may, together with further, recently collected data, serve as a basis for specific targeting of public health interventions that aim to lower risky drinking patterns and their negative consequences.

Since RSO drinkers with different cultural backgrounds or different demographics, like higher age or female gender, may select different drinking locations, research also is needed to positively influence regulations drafted by policy makers $(21,28,40,41)$. Future research should also include additional variables related to drinking location, like drinking companions or drinking motives $(42,43)$.

\section{AUTHOR CONTRIBUTIONS}

Gerhard Gmel and Meichun Mohler-Kuo are the study's main investigators. Caroline Bähler and Meichun Mohler-Kuo conceptualized the manuscript. Caroline Bähler analyzed the data and wrote the first draft of this manuscript. Michelle Dey and Simon Foster assisted in data analyses. Gerhard Gmel made major contributions to the content of the manuscript. Petra Dermota was involved in data collection and questionnaire development. All authors contributed to manuscript writing and helped to improve it.

\section{ACKNOWLEDGMENTS}

The authors would like to thank Charlotte Eidenbenz and Joseph Studer for their administrative assistance with the project. The project was funded by the Swiss National Science Foundation (33CS30_139467).

\section{REFERENCES}

1. Astudillo M, Kuntsche S, Graham K, Gmel G. The influence of drinking pattern, at individual and aggregate levels, on alcohol-related negative consequences. Eur Addict Res (2010) 16(3):115-23. doi:10.1159/000303379

2. Kraus L, Baumeister SE, Pabst A, Orth B. Association of average daily alcohol consumption, binge drinking and alcohol-related social problems: results from the German Epidemiological Surveys of Substance Abuse. Alcohol Alcohol (2009) 44(3):314-20. doi:10.1093/alcalc/agn110

3. Rehm J, Ashley MJ, Room R, Single E, Bondy S, Ferrence R, et al. On the emerging paradigm of drinking patterns and their social and health consequences. Addiction (1996) 91(11):1615-21. doi:10.1111/j.1360-0443.1996. tb02265.x

4. Stockwell T, Hawks D, Lang E, Rydon P. Unravelling the preventive paradox for acute alcohol problems. Drug Alcohol Rev (1996) 15(1):7-15. doi:10.1080/ 09595239600185611

5. White IR, Altmann DR, Nanchahal K. Alcohol consumption and mortality: modelling risks for men and women at different ages. BMJ (2002) 325(7357):191. doi:10.1136/bmj.325.7357.191

6. Wechsler H, Lee JE, Nelson TF, Kuo M. Underage college students' drinking behavior, access to alcohol, and the influence of deterrence policies. Findings from the Harvard School of Public Health College Alcohol Study. J Am Coll Health (2002) 50(5):223-36. doi:10.1080/07448480209595714

7. Gmel G, Kuntsche E, Rehm J. Risky single-occasion drinking: bingeing is not bingeing. Addiction (2011) 106(6):1037-45. doi:10.1111/j.1360-0443.2010. 03167.x

8. Rehm J, Taylor B, Room R. Global burden of disease from alcohol, illicit drugs and tobacco. Drug Alcohol Rev (2006) 25(6):503-13. doi:10.1080/ 09595230600944453

9. Demers A, Kairouz S, Adlaf EM, Gliksman L, Newton-Taylor B, Marchand A. Multilevel analysis of situational drinking among Canadian undergraduates. Soc Sci Med (2002) 55(3):415-24. doi:10.1016/S0277-9536(01)00258- 1
10. Knibbe RA, Oostveen T, van de Goor I. Young people's alcohol consumption in public drinking places: reasoned behaviour or related to the situation? $\mathrm{Br}$ J Addict (1991) 86(11):1425-33. doi:10.1111/j.1360-0443.1991.tb01728.x

11. Kuntsche E, Gmel G. Alcohol consumption in late adolescence and early adulthood - where is the problem? Swiss Med Wkly (2013) 143:w13826. doi:10.4414/smw.2013.13826

12. Kypri K, Paschall MJ, Langley JD, Baxter J, Bourdeau B. The role of drinking locations in university student drinking: findings from a national web-based survey. Drug Alcohol Depend (2010) 111(1-2):38-43. doi:10.1016/j.drugalcdep. 2010.03.018

13. Mallett KA, Varvil-Weld L, Borsari B, Read JP, Neighbors C, White HR. An update of research examining college student alcohol-related consequences: new perspectives and implications for interventions. Alcohol Clin Exp Res (2013) 37(5):709-16. doi:10.1111/acer.12031

14. Usdan S, Martin R, Mays D, Cremeens J, Weitzel JA, Bernhardt J. Self-reported consequences of intoxication among college students: implications for harm reduction approaches to high-risk drinking. J Drug Educ (2008) 38(4):377-87. doi:10.2190/DE.38.4.e

15. Ray AE, Turrisi R, Abar B, Peters KE. Social-cognitive correlates of protective drinking behaviors and alcohol-related consequences in college students. Addict Behav (2009) 34(11):911-7. doi:10.1016/j.addbeh.2009.05.016

16. Skidmore JR, Murphy JG, Martens M, Dennhardt AA. Alcohol-related consequences in African American and European American college students. J Ethn Subst Abuse (2012) 11(2):174-91. doi:10.1080/15332640.2012.675248

17. Swiss Federal Office of Public Health. National Alcohol Program 20132016. (2013). Available from: http://www.bag.admin.ch/themen/drogen/00039/ 00596/index.html?lang=de

18. Studer J, Baggio S, Mohler-Kuo M, Dermota P, Gaume J, Bertholet N, et al. Examining non-response bias in substance use research - are late respondents proxies for non-respondents? Drug Alcohol Depend (2013) 132(1-2):316-23. doi:10.1016/j.drugalcdep.2013.02.029

19. Murgraff V, Parrott A, Bennett P. Risky single-occasion drinking amongst young people - definition, correlates, policy, and intervention: a broad overview of research findings. Alcohol Alcohol (1999) 34(1):3-14. doi:10.1093/alcalc/34.1.3

20. Habgood R, Casswell S, Pledger M, Bhatta K. National Alcohol Tracking Survey 2000. APPENDIX E: Interview Schedule. 2001. (2013). Available from: http://www.aphru.ac.nz/projects/alcohol\%202000\%20apendices.htm

21. Graham K, Bernards S, Knibbe R, Kairouz S, Kuntsche S, Wilsnack SC, et al. Alcohol-related negative consequences among drinkers around the world. Addiction (2011) 106(8):1391-405. doi:10.1111/j.1360-0443.2011.03425.x

22. Wechsler H, Davenport A, Dowdall G, Moeykens B, Castillo S. Health and behavioral consequences of binge drinking in college. A national survey of students at 140 campuses. JAMA (1994) 272(21):1672-7. doi:10.1001/jama.272.21.1672

23. Hoyle R, Stephenson M, Palmgreen P, Lorch E, Donohew R. Reliability and validity of a brief measure of sensation seeking. Pers Individ Dif(2002) 32(3):401-14. doi:10.1016/S0191-8869(01)00032-0

24. Aluja A, Rossier J, García L, Angleitner A, Kuhlman M, Zuckerman M. A cross-cultural shortened form of the ZKPQ (ZKPQ-50-cc) adapted to English, French, German, and Spanish languages. Pers Individ Dif (2006) 41(4):619-28. doi:10.1016/j.paid.2006.03.001

25. Single E, Wortley S. Drinking in various settings as it relates to demographic variables and level of consumption: findings from a national survey in Canada. J Stud Alcohol (1993) 54(5):590-9.

26. Stockwell T, Lang E, Rydon P. High risk drinking settings: the association of serving and promotional practices with harmful drinking. Addiction (1993) 88(11):1519-26. doi:10.1111/j.1360-0443.1993.tb03137.x

27. Huckle T, You RQ, Casswell S. Socio-economic status predicts drinking patterns but not alcohol-related consequences independently. Addiction (2010) 105(7):1192-202. doi:10.1111/j.1360-0443.2010.02931.x

28. Kuendig H, Plant MA, Plant ML, Miller P, Kuntsche S, Gmel G. Alcohol-related adverse consequences: cross-cultural variations in attribution process among young adults. Eur J Public Health (2008) 18(4):386-91. doi:10.1093/eurpub/ ckn007

29. Temple MT, Fillmore KM. The variability of drinking patterns and problems among young men, age 16-31: a longitudinal study. Int J Addict (1985) 20(1112):1595-620.

30. Fromme K, Katz E, D'Amico E. Effects of alcohol intoxication on the perceived consequences of risk taking. Exp Clin Psychopharmacol (1997) 5(1):14-23. doi:10.1037/1064-1297.5.1.14 
31. Wells S, Graham K, Speechley M, Koval JJ. Drinking patterns, drinking contexts and alcohol-related aggression among late adolescent and young adult drinkers. Addiction (2005) 100(7):933-44. doi:10.1111/j.1360-0443.2005.001121.x

32. Kwan MY, Faulkner GE, Arbour-Nicitopoulos KP, Cairney J. Prevalence of health-risk behaviours among Canadian post-secondary students: descriptive results from the National College Health Assessment. BMC Public Health (2013) 13(1):548. doi:10.1186/1471-2458-13-548

33. Gmel G, Gaume J, Faouzi M, Kulling JP, Daeppen JB. Who drinks most of the total alcohol in young men - risky single occasion drinking as normative behaviour. Alcohol Alcohol (2008) 43(6):692-7. doi:10.1093/alcalc/agn070

34. Vaucher S, Rehm J, Benvenuti J, Muller R. Young teenagers and access to alcohol in a Swiss canton: evidence from observational testing and from a telephone survey. Addiction (1995) 90(12):1619-25. doi:10.1111/j.1360-0443.1995. tb02832.x

35. Wagenaar AC, Toomey TL, Erickson DJ. Complying with the minimum drinking age: effects of enforcement and training interventions. Alcohol Clin Exp Res (2005) 29(2):255-62. doi:10.1097/01.ALC.0000153540.97325.3A

36. Lange JE, Reed MB, Johnson MB, Voas RB. The efficacy of experimental interventions designed to reduce drinking among designated drivers. J Stud Alcohol (2006) 67(2):261-8.

37. Hartling L, Wiebe N, Russell K, Petruk J, Spinola C, Klassen TP. Graduated driver licensing for reducing motor vehicle crashes among young drivers. Cochrane Database Syst Rev (2004) 2. doi:10.1002/14651858.CD003300.pub2

38. Babor T, Caetano R, Casswell S, Edwards G, Giesbrecht N, Graham K, et al. Alkoholpolitische Massnahmen in der Schweiz im Jahre 2004 - was ist realisiert und was bringt die Zukunft? [alcohol-political measures in Switzerland in 2004 what has been realised and what brings the future?]. In: Abderhalden I, Barth A, Daeppen J, Erhard L, Frick U, Gmel G, et al. editors. Alkohol - Kein gewöhnliches Konsumgut Forschung und Alkoholpolitik. Göttingen: Hogrefe (2005).

39. Hahn RA, Kuzara JL, Elder R, Brewer R, Chattopadhyay S, Fielding J, et al. Effectiveness of policies restricting hours of alcohol sales in preventing excessive alcohol consumption and related harms. Am J Prev Med (2010) 39(6):590-604. doi:10.1016/j.amepre.2010.09.016

40. Treno AJ, Alaniz ML, Gruenewald PJ. The use of drinking places by gender, age and ethnic groups: an analysis of routine drinking activities. Addiction (2000) 95(4):537-51. doi:10.1046/j.1360-0443.2000.9545376.x

41. O'Hare TM. Drinking in college: consumption patterns, problems, sex differences and legal drinking age. J Stud Alcohol (1990) 51(6):536-41.

42. Kairouz S, Gliksman L, Demers A, Adlaf EM. For all these reasons, I do...drink: a multilevel analysis of contextual reasons for drinking among Canadian undergraduates. J Stud Alcohol (2002) 63(5):600-8.

43. Studer J, Baggio S, Deline S, N’Goran AA, Henchoz Y, Mohler-Kuo M, et al. Peer pressure and alcohol use in young men: a mediation analysis of drinking motives. Int J Drug Policy (2014) 15(14):26-7. doi:10.1016/j.drugpo.2014.02.002

Conflict of Interest Statement: The authors declare that the research was conducted in the absence of any commercial or financial relationships that could be construed as a potential conflict of interest.

Received: 14 February 2014; accepted: 26 May 2014; published online: 10 June 2014. Citation: Bähler C, Dey M, Dermota P, Foster S, Gmel G and Mohler-Kuo M (2014) Does drinking location matter? Profiles of risky single-occasion drinking by location and alcohol-related harm among young men. Front. Public Health 2:64. doi: 10.3389/fpubh.2014.00064

This article was submitted to Public Mental Health, a section of the journal Frontiers in Public Health.

Copyright (C) 2014 Bähler, Dey, Dermota, Foster, Gmel and Mohler-Kuo. This is an open-access article distributed under the terms of the Creative Commons Attribution License (CC BY). The use, distribution or reproduction in other forums is permitted, provided the original author(s) or licensor are credited and that the original publication in this journal is cited, in accordance with accepted academic practice. No use, distribution or reproduction is permitted which does not comply with these terms. 